\title{
Metal Oxide Gas Biomarkers of Diseases for Medical and Health Applications
}

\author{
Aroutiounian VM* \\ Yerevan State University YSU, 1 Alex Manoukian, Armenia \\ *Corresponding author: Aroutiounian VM, Yerevan State University YSU, 1 Alex Manoukian, Armenia
}

\section{ARTICLE INFO}

Received: 蔧 July 06, 2020

Published: 幽 August 04, 2020

Citation: Aroutiounian VM. Metal Oxide Gas Biomarkers of Diseases for Medical and Health Applications. Biomed J Sci \& Tech Res 29(2)-2020. BJSTR. MS.ID.004780.

\section{ABSTRACT}

One of the most important directions of modern medicine is non-invasive diagnostics of the patient, based on the analysis of exhaled air in a special device. Data on the surveillance capabilities of various diseases in the allocation of specific gases are collected. The potential of various semiconductor chemical resistors made from metal oxide semiconductors to diagnose disease has been reviewed. Corresponding low-cost detectors are developed which can detect small concentrations of exhaled air.

Keywords: Microelectronic Semiconductor Gas Sensor; Breath Analysis; Metal Oxide

\section{Introduction}

Human exhaled breath contains nitrogen (about 78\%), oxygen (16\%), carbon dioxide (4\%-5\%, hydrogen (5\%), and water vapor. Besides, in the case of a healthy person, the exhaled air contains rather small concentrations of nitric oxide $\mathrm{NO}$, ammonia $\mathrm{NH}_{3}$, carbon monoxide $\mathrm{CO}$, hydrogen dioxide $\mathrm{H}_{2} \mathrm{O}_{2}$ and sulphide $\mathrm{H}_{2} \mathrm{~S}$ as well as ethanol, acetone, etc. A remarkable increase in the concentration of last gases indicates the presence of various diseases in the patient. The metabolic excreted products diffuse into the inhaled air though the alveoli in the lungs and then the air is rejected. That is, a multi-component gas mixture formed, which accumulates first in the alveolus of the lungs. It is necessary to look for the cause of this either in incoming food (sources of volatile substances), or in internal organs, blood, blood vessels, sweat or urine. Today the medical doctor not only polls and examines the patient but also sends it to the lab-tests of blood, urine, perform an electrocardiogram, etc. But, for example, today's periodic monitoring of glucose concentrations in the blood induces acute pain, risk of virus (e.g., hepatitis B) infection from needles, and other difficulties infrequent monitoring.

Intensive investigations of bio-safe small-sized semiconductor gas sensors for medical applications are carried out in recent years. Requirements for such biomarkers are their high sensitivity, selectivity, and stability to very low concentrations of gases, mainly exhaled by a living organism. The exhaled gases such as $\mathrm{NO}_{\mathrm{x}^{\prime}}$ acetone, ethanol, $\mathrm{NH}_{3}, \mathrm{H}_{2} \mathrm{~S}$, and $\mathrm{H}_{2} \mathrm{O}_{2}$ can be used for sensors to diagnose various diseases. Non-invasive diagnostics of the patient, based on the analysis of exhaled air in a special device, allow only to make exhalation and after a few seconds-one minute to get the results of the analysis. The prospect of a non-invasive diagnosis is obvious - full safety from viral hepatitis, AIDS, and other infections.

Exhaled breath contains about 3500 volatile organic compounds (VOCs) that are the products of metabolism. But it is necessary to take into account that several important gases at some concentration in the air are immediately dangerous to life or health. According to the results of the study of volatile substances exhaled by a person, it is possible to judge the nature of nutrition - sufficiency of carbohydrates, excess fat and alcohol. By excess or lack of any chemical component in the spectrum of exhaled air, hereditary enzymopathy and the presence of various diseases can also be assumed. Due to the large surface of the lungs, volatile substances (ethanol, ammonia, acetone, and others) very quickly pass from the bloodstream to the external environment with exhaled air.

It is the mixture of various molecules secreted by a man that makes up the individual, unique smell of the patient. In a number of cases, this smell allows to immediately make the correct diagnosis. The sweet "liver odor" of explosives is due to a violation of the exchange of aromatic compounds and the accumulation of the product of the conversion of methionine - methyl mercaptan. This 
smell of raw liver often haunts pancreatic cancer patients and may be one of the first symptoms of this ailment. The smell of ammonia in explosives is typical for kidney and uremia diseases, the "mouse smell" - for patients with hereditary phenylketonuria, the smell of syrup is in violation of the metabolism of fatty acids and the accumulation of keto acids and amino acids in the blood and urine, the smell of acetone - in patients with diabetes mellitus. A sharp specific smell from the mouth is a symptom of a number of diseases of the oral cavity and stomach (stomatitis, periodontal disease, gastritis, peptic ulcer, and stomach cancer).

In cardiopulmonary insufficiency, unpleasant sour smell of under oxidized metabolic products associated with incomplete combustion of proteins, fats, and carbohydrates in the liver often comes from patients. An unusual persistent smell is a formidable symptom of a growing tumor of the anterior brain. It turned out that with a stroke with an unfavorable outcome, much less acetone is released in patients than in healthy people. At the same time, diabetics, who also fell into a coma, exhale tens and hundreds of times more acetone than healthy ones. The content of acetone and ethanol is significantly different from healthy individuals (in patients with diabetes mellitus, cardiovascular disease, in children with bronchial asthma, diathesis, in pregnant women with toxicities of the first half of pregnancy). We also note that it is possible to successfully detect using semiconductor sensors odorless substances, such as carbon monoxide (carbon monoxide) or carbon dioxide.

\section{Capabilities of Detection of Various Diseases}

Capabilities of detection of the various diseases using the analysis of the breath are discussed below. Data on the surveillance capabilities of diseases in the allocation of specific gases are collected below in Table 1. Naturally, assembled here material cannot be considered as exhaustive one. Note also that the analysis of the breath allows to detect (diagnose) cancer of stomach and ovaries, rheumatoid disease, acute myocardial infarction, gum disease, tooth decay, bacterial imbalance on the tongue, impacted wisdom teeth, dehydration, sleep apnea, gastric, stomach ulcers duodenal ulcers and other diseases can be carried out. The presence of heptane, xylenes, octane, ethylbenzene, styrene, decane, toluene, benzene, and formaldehyde allow detecting lung cancer.

\section{Methods of the Study of the Compositions of Explosives}

From the middle of the 20th century to the present day, chromatography and mass spectrograph are among the most widely used analytical methods for studying explosives [1-5]. Many volatile metabolites were determined by these methods in explosives, many of which are used as markers of inflammation. Their specificity and sensitivity for the diagnosis of many diseases are determined. In addition to chromatography and mass spectrograph, radioimmune and enzyme-linked immunosorbent assays, spectrophotometry, fluorometric and chemiluminescent methods were proposed, the protein matrix and tumor necrosis factor are studied, etc. In medicine, when studying gas exchange, gas analyzers are used to measure the concentration of carbon dioxide, oxygen, and nitrogen in the inhaled and the exhaled gas mixture, to study blood gases and to measure the concentration of the indicator gas in the artificially created mixture when determining the number of respiration parameters (instruments for measuring gas concentration in a gas mixture). In recent years, ionic and proton mass spectroscopic methods and gas chromatography has been used. Of course, the possibility of physical-chemical studies of gas-phase are not limited to such analysis. Samples of internal abdominal gases can collect and examine from different sections of the bronchi with bronchoscopy, from the stomach with gastroscopy, from the colon with colonoscopy, from the bladder with cystoscopy, etc.

\section{Semiconductor Gas Sensors of Exhaled Breath}

It is important today we develop the individual metabolic profile of the patient. The equipment mentioned above is expensive and bulky, it is necessary to develop cheap, small-size and bio-safe measuring setups which can be used individually by a medical doctor and each patient elsewhere out of hospitals and specialized centers. Therefore, the use of semiconductor gas sensors for detecting the concentration of detectable gas (acetone in diabetes, for example) is widely discussed in the literature (see, for example, [6-21]).

Different metal oxide semiconductors for the manufacture of such sensors are proposed and investigated because they are not oxidized materials, have stable in time characteristics, and can work at its remarkable pre-heating. Determination of the concentration of chemical compounds in explosives using gas sensors will allow the diagnosis of the disease already in the early stages and will make it possible to control treatment. As was mentioned above, by the concentration of acetone and the amount of current passing through the semiconductor sensor, for example, one can judge the degree of diabetes, acute heart failure, lung cancer; hydrogen peroxide and nitric oxide--asthma and other pulmonary diseases, cancer of the digestive system; ammonia and hydrogen sulfide - hepatitis and cirrhosis; hydrogen and methane, a number of diseases of the digestive system, etc (Table 1). The current study of head, ovarian, bladder, prostate, kidney, gastric, as well as neck cancer, Crohn's disease, ulcerative colitis, idiopathic and atypical Parkinson's disease, multiple sclerosis, pulmonary hypertension, and other diseases is started now using semiconductor nanoarrays and artificial intelligence methods. 
Table 1.

\begin{tabular}{|c|c|}
\hline Gases & Exhalation and Diagnostic Significance \\
\hline Nitrogen oxide (NO) & $\begin{array}{l}\text { Respiratory diseases [asthma, chronic obstructive pulmonary disease (COPD), etc] Rhinitis digestive diseases Iin- } \\
\text { flammation in the stomach (gastritis, hepatitis, colitis) Liver transplant rejection Cystic fibrosis Encephalopathy Virus } \\
\text { Covid-19 Helicobacter pylon digestive cancer }\end{array}$ \\
\hline Ammonia $\left(\mathrm{NH}_{3}\right)$ & $\begin{array}{l}\text { Diseases of the kidneys and liver (kidney failure, liver dysfunction, } 29 \text { hepatic encephalopathy, renal insufficiency } \\
\text { in nephritis, idiopathic hypertension, atherosclerosis of renal artery, toxicities and nephropathy of pregnant, toxic } \\
\text { defeats of kidneys, paucity of the liver in jaundice, cirrhosis of the liver) Acute and chronic radiation sickness The } \\
\text { metabolism of monoamine in the brain Uremia Swelling of brain, Type-II Alzheimer's disease Peptic ulcer Halitosis }\end{array}$ \\
\hline Hydrogen Peroxide $\left(\mathrm{H}_{2} \mathrm{O}_{2}\right)$ & $\begin{array}{l}\text { The same respiratory diseases Lung cancer Weakened respiratory lung function, etc.) The acute and chronic radiation } \\
\text { sickness Diabetes Virus Covid-19 Neutrophilic inflammation }\end{array}$ \\
\hline Acetone $\left(\mathrm{C}_{6} \mathrm{H}_{6} \mathrm{O}\right)$ & $\begin{array}{c}\text { Diabetes Diabetic ketoacidosis The pancreas in acute pancreatitis and execute-destructive dietary and severe balance } \\
\text { failure at lung cancer Chronic liver disease }\end{array}$ \\
\hline Hydrogen sulfide $\left(\mathrm{H}_{2} \mathrm{~S}\right)$ & Airway inflammation Oral and dental heath Asthma Intraoral halitosis \\
\hline Methane & $\begin{array}{l}\text { Gastrointestinal disorders (Malabsorption hydrocarbons) Colorectal cancer } \\
\text { Obesity Irritable bowel syndrome inflammatory Anorexia }\end{array}$ \\
\hline $\mathrm{CS}_{2}$ and pentane & Risk factor in coronary artery diseases, Schizophrenia \\
\hline Ethylene $\left(\mathrm{C}_{2} \mathrm{H}_{4}\right)$ & $\begin{array}{l}\text { Oxygen stress, Lipid peroxidation internals at acute myocardial infarction } \\
\text { Destruction caused by free radicals Uremia }\end{array}$ \\
\hline Ethane $\left(\mathrm{C}_{2} \mathrm{H}_{6}\right)$ & $\begin{array}{l}\text { Lipid peroxidation in liver transplant peroxide Marker-assisted oxidation of lipids Schizophrenia COPD Interstinal } \\
\text { lung desease Asthma Cystic Fibrosis Heart Failure Inflammatory bowel disease Vitamin E deficiency Breast cancer } \\
\text { Ulcerative colitis }\end{array}$ \\
\hline Methanol & Diseases of the central nervous system Lung and breast cancer \\
\hline Ethanol & Alcoholism Diabetes/Hyperglycemia \\
\hline Isotopic modification & $\begin{array}{l}\text { Infection with the bacterium Helicobacter pylori passage of food through the gastrointestinal tract the overgrowth of } \\
\text { bacteria lactose Digestion pancreatic Dysfunction Malabsorption liver dysfunction, including cirrhosis the metabolism } \\
\text { of bile glucose metabolism }\end{array}$ \\
\hline Vapors of urine & Gastroenterology \\
\hline Pentane & $\begin{array}{l}\text { Breath and lung cancer. Acute myocardial infarction Heart titrant rejection Arthritis The exacerbation of asthma Oxi- } \\
\text { dative stress Physical and mental stress Inflammatory bowel diseases Sleep apnea Ischemic heart disease Myocardial } \\
\text { infraction Liver disease Schizophrenia Sepsis COPD Cystic fibrosis }\end{array}$ \\
\hline Aldehydes & $\begin{array}{l}\text { Lung, breast and childhood cancer Tuberculosis Wilson's disease } \\
\text { Hemochromatosis associated with alcoholic liver disease, smoking, oxidative stress, diabetes and atherosclerosis hy- } \\
\text { pertension, aging Cerebral Ischemia Alzheimer's and Parkinson's Diseases Amyotrophic Lateral Sclerosis Lou Gehrig's } \\
\text { Disease Wernicke's Encephalopathy }\end{array}$ \\
\hline Dimethyl & $\begin{array}{l}\text { Lung cancer Cystic fibrosis Intra- and extraoral halitosis Chronic liver disease Hypermethioninemia and carbonyl } \\
\text { sulfides }\end{array}$ \\
\hline Isoprene & Lung cancer Castaic ulcer Heart failure Diabet Lipid metabolism Disorder Hypercholesterolemia COPD Flu Virus \\
\hline
\end{tabular}

Metal oxide semiconductors n-type $\mathrm{SnO}_{2}, \mathrm{ZnO}, \mathrm{WO}_{3}, \mathrm{TiO}_{2}, \mathrm{MoO}_{3}$, $\mathrm{In}_{2} \mathrm{O}_{3}, \mathrm{Fe}_{2} \mathrm{O}_{3}$ and p-type $\mathrm{CuO}, \mathrm{NiO}, \mathrm{Cr}_{2} \mathrm{O}_{3}, \mathrm{Mn} 3 \mathrm{O} 4$ are used during breath analysis $[6,15,16]$, Some interesting papers about sensors promising for breath analysis listed in Refs. [7,9-12,14]. Note that the disease diagnosis using exhaled breath is still in the nascent stage and needs further improvement for clinic applications.

Detection of $\mathrm{NO}$ and $\mathrm{NH}_{3}$ for the Diagnosis of Asthma and

\section{Renal Disease}

The most important biomarkers of diseases in human body are nitic oxide. ammonia, acetone, hydrogen dioxide and sulphide. Of course, a lot of information can be received from detection of other exhaled gases (Table 1). Villi-like $\mathrm{WO}_{3}$ nanostructures show high gas responses (Rgas/Rair) $\sim 30$ to $0.2 \mathrm{ppm} \mathrm{NO}$ at $200^{\circ} \mathrm{C}$ [19]. It is shown also that $\mathrm{WO}_{3}$ nanotubes exhibit high responses to 1 ppm NO. These results were obtained in highly humid (RH > 80\%) atmospheres. BOSCH Healthcare Solutions announced a monitor that allowing measurements of fractional exhaled nitric oxide (FENO) for the diagnosis of asthma $[22,23]$. So, it is established that nitric oxide is an excellent biomarker of bronchial asthma.

The potential of $\mathrm{WO}_{3}$ nanostructures for the diagnosis of asthma was demonstrated. This device consists of pretreatment components that precondition the exhaled gas and sensing components that measure FENO [24-27]. The initial stages of renal disease can be diagnosed by measuring $\mathrm{NH}_{3}$ and $\mathrm{H}_{2} \mathrm{~S}$ vapors in exhaled breath [28-30]. End-stage renal disease (ESRD) requires time-consuming, expensive, and inconvenient hemodialysis, which significantly decreases the quality of life for patients. If the nephron function is completely lost, kidney transplantation needs to be 
considered. The breath $\mathrm{NH}_{3}$ concentration of ESRD patients ranges around 4,9 ppm in contrast to $0.96 \mathrm{ppm}$ for healthy individuals. Exhaled ammonia can be also used to diagnose liver disease and helicobacter pylori infection. $\alpha-\mathrm{MoO}_{3}$ has his selectively to $\mathrm{NH} 3$ detection at sub-ppm levels even in highly humid atmospheres. It can be used for the diagnosis of renal failure. $\mathrm{MoO}_{3}$ and $\mathrm{WO}_{3}$ often show high response to basic amines such as trimethylamine, triethylamine, and butylamine.

Exhaled breath condensate and nitric oxide gas inhalation as a potential specimen for diagnosing COVID-19. As was mentioned above, breath gas analysis is non-invasive and has a number of possible applications, including the detection of different diseases and viruses, monitoring of metabolic processes, the study of pharmacokinetics, screening for disease biomarkers as well as drug testing. Coronavirus disease 2019 (COVID-19) is an emerging condition threatening the biosecurity of all peoples on the planet. Common signs of infection include respiratory symptoms, fever, cough, shortness of breath and breathing difficulties. In more severe cases, the infection can cause pneumonia, severe acute respiratory syndrome, kidney failure, and even death. The Covid- 19 particles detected in the lungs of patients. The virus particles were generally spherical with distinctive spikes ranging from 9 to $120 \mathrm{~nm}$, giving the appearance of a solar corona [31-33].

It was observed that prior heart attacks or strokes, diabetes, hypertension, asthma, and COPD diseases were at a higher risk of dying from the Covid-19 disease. All such patients should also stock up on all necessary home diagnostics including glucometers and other supplies.

Exhaled breath condensate (EBC) could be considered a more appropriate sample to follow the virus. EBC samples should be tested as a noninvasive sampling method in clinics, since it seems a promising specimen for the diagnosis of patients with COVID-19 infections. EBC is a condensed form of small droplets of the lung lining fluid [34] which is normally exhaled and contains a variety of components from small ions to proteins and organelles, even viruses, fungi and bacteria [35-37]. EBC samples could be easily collected using the collection chamber cooled down the temperature of from 0 to $-25^{\circ} \mathrm{C}[34,38]$. After 2.5 minutes, exposure to 10 -ppm hydrogen peroxide or $2 \mathrm{ppm}$ triemethylene glycol vapor resulted in 99\% inactivation influenza viruses on surfaces [39].

Barnes, and his colleagues at the National Heart and Lung Institute of Great Britain have shown that the mechanism that keeps the bronchioles of the lungs open is largely controlled by nitric oxide. The formation of gas from the amino acid L-arginine is provided by the cells lining the lungs and macrophages, the forms of enzymes necessary for its production. It has now been proven that simple nitric oxide (NO) is involved in the regulation of many physiological functions. Satisfying the body's needs for nitric oxide by inhalation leads to relaxation of blood vessels, an increase in the immune response, regulation of the functioning of the genome and the activity of the nervous system, and can also have a noticeable therapeutic effect in asthma and other lung-related diseases, including pulmonary hypertension and respiratory distress syndrome. The use of L-arginine as a dietary supplement, from which the cells of the respiratory tract release nitric oxide, significantly increased the content of this gas in exhaled air. No significant changes in heart rate and blood pressure occurred in patients. The intake of L-arginine as a dietary supplement increases the production of NO by the body and the lungs and that this may find application in the treatment of diseases in which nitric oxide is produced in insufficient quantities. For example, in asthma, the concentration of NO is in the range of 30-100 ppb. Now it has been reported that an increase in the concentration of NO in the body can contribute to the recovery of patients from CoVid99 coronavirus. The treatment with nitric oxide NO reversed pulmonary hypertension, improved severe hypoxia and shortened the length of ventilatory support as compared to matched control patients with Severe Acute Respiratory Syndrome (SARS) Coronavirus. Nitric Oxide Gas as drag greatly increased the survival rate of SARSCoV-infected eukaryotic cells, suggesting direct antiviral effects of NO. In a subsequent in-vitro study, NO donors (e.g. S-nitroso-Nacetylpenicillamine) greatly increased the survival rate of SARSCoV-infected eukaryotic cells, suggesting direct antiviral effects of NO. Coronavirus responsible for SARS-CoV shares most of the genome of COVID-19 is indicating potential effectiveness of inhaled NO therapy in these patients. Prolonged treatment with inhaled NO can lead to increased methemoglobin levels. Blood levels of methemoglobin will be monitored via a non-invasive CO-oximeter. It was also shown in Protokol [40] that inhaled nitric oxide gas (iNO) has antiviral activity against other strains of coronavirus. The primary aim of this study is to determine whether inhaled NO improves the situation. In clinical settings, NO gas has been approved by the US Federal Drug Administration for the treatment of pulmonary hypertension of the newborn in the presence of hypoxic respiratory failure. In 2004, during SARS-CoV outbreak, it was reported the use of inhaled NO gas (iNO) in six patients with severe symptoms. Treatment with iNO reversed pulmonary hypertension, improved remarkably severe hypoxemia, and shortened the length of ventilatory support as compared to matched control patients with SARS-CoV [39]. In a subsequent in-vitro study, nitric oxide (NO) donors greatly increased the survival rate of SARS-CoVinfected eukaryotic cells, suggesting direct antiviral effects of NO $[39,40]$. Due to similarities with the Coronavirus responsible for SARS and COVID-19, scientists indicated the potential effectiveness of iNO therapy.

It is necessary to make the following comments about the safety of the use of $\mathrm{NO}$ gas. It reacts with oxygen to form $\mathrm{NO}_{2}$, which may cause damage to lung tissues. Moreover, NO oxidizes ferrous $\mathrm{Hb}$ to form Met-Hb, which is unable to transport and release oxygen to tissues. Based on the present literature and Food and Drug Administration reports, the risks of breathing iNO at $80 \mathrm{ppm}$ for 24 
hours are minimal when Met- $\mathrm{Hb}$ levels and $\mathrm{NO} / \mathrm{NO}_{2}$ delivery levels are carefully monitored [40]. To improve safety, in the present trial, iNO is administered and monitored by trained clinicians. The $\mathrm{NO}_{2}$ will be monitored and maintained at levels of below $2 \mathrm{ppm}$. Met- $\mathrm{Hb}$ is continuously monitored by non-invasive CO-oximetry.

\section{Detection of Acetone for Diagnosing Diabetes}

Diabetes patients use fat instead of glucose for energy and ketones are produced by the liver during fatty-acid metabolism. The concentrations of breath acetone in diabetes patients are reported to be higher than $1.8 \mathrm{ppm}$ while those of healthy people are lower than $0.8 \mathrm{ppm}$. Breath acetone concentrations can increase during ketogenic or low carbohydrate diets that are known to induce ketosis. It allows checking the effectiveness of ketosis-based dietary programs for healthy people. Among all other sensing materials, metal oxides show the highest responses to acetone. Various oxide sensing materials mentioned below allow enhancing selectivity and sensitivity to acetone under highly humid atmospheres.

There are $\mathrm{Pt}$, $\mathrm{Rh}$ or Ni-loaded $\mathrm{TiO}_{2}, \mathrm{SnO}_{2}$ nanotubes/ hierarchical nanofibers and $\mathrm{WO}_{3}$ hemitubes/nanofibers, having an average size of 2 to $3 \mathrm{~nm}$ [41-43], Pt-loaded [44], Pd-loaded $\mathrm{ZnO} / \mathrm{ZnCo}_{2} \mathrm{O}_{4}$ hollow spheres [42], $\mathrm{RuO}_{2}$-loaded $\mathrm{WO}_{3}$ nanofibers [43], $\mathrm{Rh}_{2} \mathrm{O}_{3}$-loaded $\mathrm{WO}_{3}$ nanofibers [44], and PdO-loaded $\mathrm{Co}_{3} \mathrm{O}_{4}$ hollow nanocages [45]. These fabricated nanostructures show great promise to be utilized as portable breath sensors for diabetes disease diagnosis. Note that $\mathrm{SnO}_{2}, \mathrm{ZnO}, \mathrm{Fe}_{2} \mathrm{O}_{3}, \mathrm{WO}_{3}$, and other metal oxide gas sensors often show similar responses to acetone, ethanol, and other VOCs. Accordingly, analyses from intoxicated diabetes patients, or the presence of small amounts of alcohol in the mouth, may not provide reliable diagnoses. Pure and catalyst loaded has been used as the most common and representative sensing materials for the selective detection of acetone [46-49].

\section{Detection of $\mathrm{H}_{2} \mathrm{~S}$ for Diagnosing Halitosis}

The degradation of S-containing amino acids in the oral cavity, upper/lower respiratory tract, and alveolar exchange with blood lead to halitosis. It is detectable as highly odorous gases with concentrations less than $1 \mathrm{ppm}$, that can be used to diagnose for hepaticus and metabolic disorder. $\mathrm{CuO}$ alone and as additive materials to $\mathrm{SnO}_{2}, \mathrm{In}_{2} \mathrm{O}_{3}$, and $\mathrm{ZnO}$ have been used as the sensing material. The conversion of the p-type semiconducting $\mathrm{CuO}$ into metallic CuS leads to the form of junction n-type semiconductormetallic $\mathrm{CuS}$. The doping of hollow $\mathrm{SnO}_{2}$ spheres with $\mathrm{CuO}$ decreased the humidity dependence of the sensing characteristics to negligible levels without sacrificing high selectivity and sensitivity H2S at $80 \%$ $\mathrm{RH}$. Therefore, $\mathrm{CuO}$ is effective both in dry air and exhaled breath.

Liang et al. [50] reported that the $\mathrm{CuO}$-loaded $\mathrm{In}_{2} \mathrm{O}_{3}$ nanofiber sensor showed reversible $\mathrm{H}_{2} \mathrm{~S}$ sensing characteristics above $300^{\circ} \mathrm{C}$. Doping Mo on $\mathrm{ZnO}$ nanowires not only increased selectivity to $\mathrm{H}_{2} \mathrm{~S}$ but addition significantly enhanced the reversibility of the $\mathrm{H}_{2} \mathrm{~S}$ sensing characteristics. Ag was also reported to be an effective addition. Yoneda et al. [51] provided a mini review on various techniques for the analysis of halitosis. Some other investigations of the $\mathrm{H}_{2} \mathrm{~S}$ sensing characteristics reported in [41,50-53].

\section{Investigations of Metal Oxides Biomarkers Sensitive to Hydrogen, Hydrogen Dioxide, Isoprene, and Aldehides}

Hydrogen sensors implemented at Yerevan State University (YSU) [53-55] are highly sensitive. It is important that sensors are very sensitive even at relatively high gas concentrations. Remember that the concentration of hydrogen exhaled by a healthy patient is already about $6 \%$, and with the diseases noted above in the Table 1 , this concentration is even higher. Therefore, the use of our hydrogen sensors for biomedical applications is very promising.

As for the hydrogen peroxide $\mathrm{H}_{2} \mathrm{O}_{2}$ sensors developed at YSU [56-59], the detection of low concentrations of exhaled gas (in the range of less than one up to one hundred ppm), which is just characteristic of our sensors, is already required here. In addition, the dependence of the sensor response on gas concentration is linear, which facilitates the processing of data and the design of a meter of the gas concentration. Pure $\mathrm{SnO} 2$ and other metal oxides without corresponding doping have a low sensitivity (response) to gases at a sufficiently high working (operating) temperature of their preliminary heating. In particular, we have shown that the functionalization of the $\mathrm{SnO}_{2}$ film structures with multilayer carbon nanotubes (MWCNT) and Ru catalysts leads to a remarkable decrease in the sensor operating temperature and a significant increase in the response signal to acetone, methanol, ethanol, isobutane, and toluene vapors. Several complex phenomena take place in such functionalized nanocomposites. Today it is impossible to imagine the full picture, but we must take into account the following: Note that MWCNTs have a developed surface and a nanoscale structure that exposes many parts of the surface with which gases can react; CNTs have a much smaller sensitivity to gases as well as the electrical conductivity of CNTs is much higher than the electrical conductivity of metal oxides. Consequently, the doping of metal oxides with CNTs reduces the resistance of sensitive metal oxide materials and opens up the possibility of more intense passage of charge carriers from one ohmic contact to another. Since the metal oxide film is mainly an n-type semiconductor, and MWCNTs have p-type semiconductor characteristics, many depleted layers are formed in such multi-grain films. Note that each time one depleted region is located on the surface of the metal oxide, and the other is at the interface between the metal oxide nanoparticle and MWCNTs. The formation of nanochannels and heterojunctions leads to increased gas sensitivity of such gas sensors due to a decrease in the work function (barrier height) and an increase in the conductivity of the sensitive layer. The same phenomena were detected in $\mathrm{Fe}_{2} \mathrm{O}_{3}$ and ZnO samples doped with CNTs $[60,61]$. 
The investigations of the response of metal oxide sensors to isoprene are carried out in [62]. Gaseous aldehyde breath biomarkers were proposed [63]. Ni-doped and Co-doped $\mathrm{ZnO}$ nanowires, $\mathrm{Co}_{3} \mathrm{O}_{4}$ (mesoporous, $\mathrm{Cr}$-doped nanocomposites, and $\mathrm{Pd}$ loaded shell sphere and hierarchical nanosheets), $\mathrm{Cr}_{2} \mathrm{O}_{3}-\mathrm{ZnCr}_{2} \mathrm{O}_{4}$ nanocomposites, $\mathrm{NiO}-\mathrm{NiMoO}_{4}-\mathrm{SnO}_{2}$ nanocomposites, $\mathrm{Cr}$-doped $\mathrm{NiO}$ hierarchical nanosheets, $\mathrm{Pd}-\mathrm{SnO}_{2}$ film with $\mathrm{Co}_{3} \mathrm{O}_{4}$ overlayer are very promising materials for detection of lung cancer [6].

\section{Detection of Volatile Organic Compounds for a Cancer}

Researchers have investigated different gases of lung cancer by comparing the breaths of healthy people $[6,64]$. Volatile organic compounds (VOCs) are reported as biomarker gases of the lung, breast, colon and prostate cancers. Note that most lung-cancer biomarker gases, except a few, contain benzene rings. Pure CNT or graphene-based sensing materials generally do not exhibit notable responses to large gases at room temperature or temperatures less than $100^{\circ} \mathrm{C}$. P-type semiconductors as gas sensing materials for benzene-derived gases, such as xylene, toluene, and benzene itself, can be used during measurements of lung cancer.

Of course, lung cancer can be diagnosed via the detection of a single biomarker gas. However, to increase diagnosis precision, the diagnosis of lung cancer using the electronic nose technology is preferable.

\section{Gas Detectors}

Many interesting detectors are developed today for health monitoring and diagnosis -pulsoximeters, diabet measurers, Doppler radar sensors, smartphone sensors with camera and microphone, custom Bio-VOC injection systems etc [65-67]. Such detectors use different methods and phenomena in process of investigations of illnesses, mostly have large sizes and expensive, realize invasive monitoring. The intensive work on the manufacture of new bio-safe small-sized equipment using semiconductor gas sensors for medical applications and diagnose various diseases are carried out in recent years. Requirements for such biomarkers are their high sensitivity, selectivity, and stability to very low concentrations of gases, mainly exhaled by a living organism. Noninvasive diagnostics of the patient, based on the analysis of exhaled air in a special device, allow only to make exhalation and after a few seconds-one minute to get the results of the analysis. The prospect of a non-invasive diagnosis is obvious - full safety from viral hepatitis, AIDS, and other infections.

Note that semiconductor sensors of various gases have been developed in Department of Semiconductor Physics and Microelectronics and the Scientific Center for Semiconductor Devices and Nanoelectronics at YSU. Sensors at YSU are sensitive to vapors of acetone, ammonia, nitrogen oxides, iso-butane, ammonia, hydrogen sulfide, hydrogen, various alcohols, toluene, combustible gases, hydrogen peroxide, propane, propylene glycol, formaldehyde, dimethylformamide, dichloroethane, gasoline, carbon monoxide and smoke arising in the early stages of a fire (see some references above and $[68,69])$. As part of the NATO grant, small-sized semiconductor sensors for nerve gases of chemical weapons (sarin, mustard gas) have been developed in YSU [70]. Successful tests of such sensors were carried out at the Czech Military Academy. Studies of hydrogen and hydrogen peroxide sensors were carried out jointly with colleagues from the USA, Hungary, Czechia, France and the Republic of Korea. Note that the sensors at YSU are stable in time, have smaller sizes, and cheap.

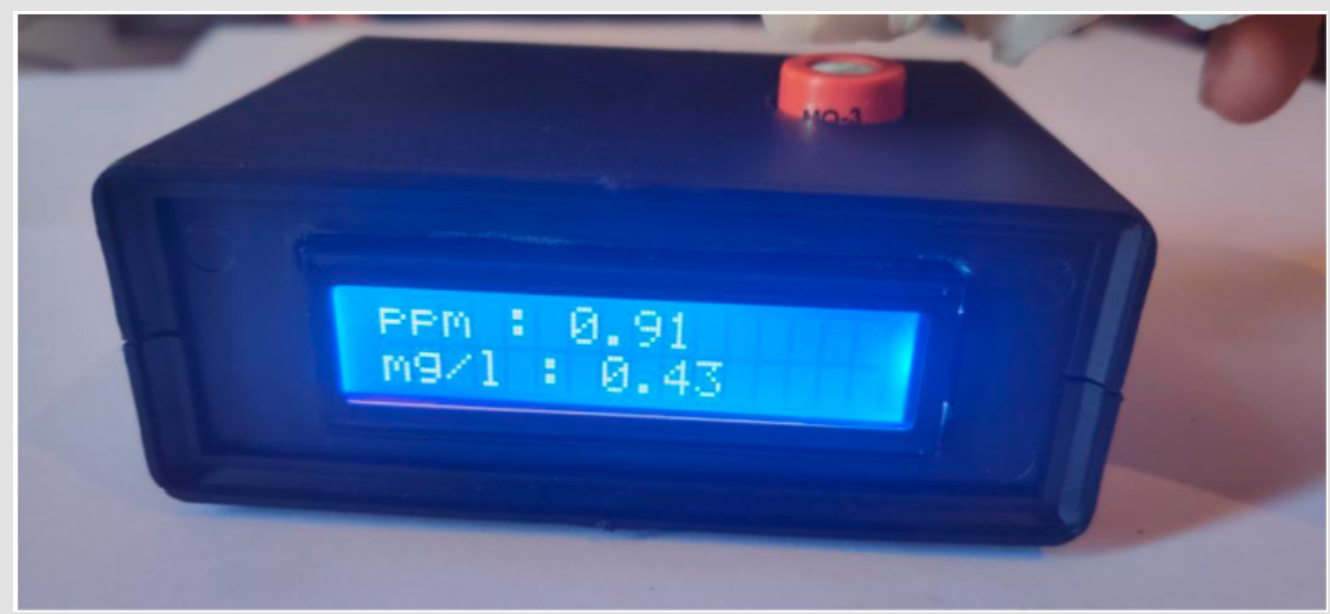

Figure 1: Arduino Nano acethone gas detector [71]

We developed different gas analyzers (see, for example [68]). Figure 1 shows the possibility of implementing such a acetone gas detector using a programmable board and the Arduino Nano memory [71]. Earlier, we developed also a device, which allows us to measure simultaneously three gases-methane, carbon monoxide, and hydrogen. Note also that pretreatment components such as dehumidifiers, preconcentrates, and flow sensors are very important for precise analysis. To miniaturize the system and achieve in situ 
diagnosis, the adsorption of analyte gases, interference gases, and moisture needs to be significantly improved.

\section{Conclusion}

One of the most important directions of modern medicine is non-invasive diagnostics of the patient, based on the analysis of exhaled air in a special device. Data on the surveillance capabilities of various diseases in the allocation of specific gases are collected. The potential of various semiconductor chemical resistors made from metal oxide semiconductors to diagnose disease has been reviewed. For disease diagnosis from exhaled breath, pure and catalyst-loaded semiconductor chemical resistors sensing materials for specific biomarker gases are reported. In particular nano sensors were discussed having the potential to detect asthma, renal disease, diabetes, halitosis, and lung cancer. The humidity and temperature dependencies of various sensing characteristics need to be decreased to negligible levels through the complete understanding of gas-sensing mechanisms and the interaction between moisture and the sensing surface. Corresponding low-cost detectors are developed which can detect small concentrations of exhaled air.

\section{Conflicts of Interest}

The authors have no conflicts of interest to declare.

\section{References}

1. Amann A, Poupart G, Telser S, Ledochowski M, Schmid A, et al. (2004) Applications of breath gas analysis in medicine. Int J Mass Spectr 239(2 3): 227-233.

2. Beccaria M, Bobak C, Maitshotlo B, Mellors TR, Purcaro G, et al. (2018) Exhaled human breath analysis inactive pulmonary tuberculosis diagnostics by comprehensive gas chromatography-mass spectrometry and chemometric techniques. J Breath Res 13(1): 016005.

3. Lamote K, Brinkman P, Vandermeersch L, Vynck M, Sterk PJ, et al (2017) Breath analysis by gas chromatography-mass spectrometry and electronic nose to screen for pleural mesothelioma: A cross-sectional case-control study. Oncotarget 8(53): 91593-91602.

4. Markar SR, Wiggins T, Antonowicz S, Chin ST, Romano A, et al. (2018) Assessment of a Noninvasive Breath Test for Diagnosis of Oesophagogastric Cancer. JAMA Oncol 4(7): 970-976.

5. Abbott SM, Elder JB, Spanel P, Smith D (2003) Quantification of acetonitrile in exhaled breath and urinary headspace using selected ion flow tube mass spectrometry. Int J Mass spectrom 228(2-3): 655-665.

6. Aroutiounian VM (2019) Metal oxide nanosensors. J Contemporary Physics Arm Acad Sci 54: 356.

7. Cao F, Li C, Li M, Li H, Yang B (2018) ZnO nanorod walled carbon nanotube nanocomposite for ethanol vapor detection. Micro and Nano Letters 13: 779-783.

8. El Achhab M, Schierbaum K (2016) Gas sensors based on plasmaelectrochemically oxidized titanium foils. Journal of Sensors and Sensor Systems 5: 273-281.

9. Gonzales WV, Mobashsher AT, Abbosh A (2019) The Progress of glucose monitoring. A review of invasive to minimally and non-invasive techniques, devices and sensors. Sensors 19(4): 800.

10. Kien N, Hung C, Ngoc TM, Thanh Le DT, Nguyen, et al. (2017) Lowtemperature prototype hydrogen sensors using $\mathrm{Pd}$ decorated $\mathrm{SnO}_{2}$ nanowires for exhaled breath applications. Sens Actuators B: Chemocal 253: $156-163$

11. Narjinary M, Sen P, Pal M (2017) Enhanced, and selective acetone sensing properties of $\mathrm{SnO}_{2}$-MWCNT Nanocomposites. Promising materials for diabetes sensor. Materials and Design 115: 158-164.

12. Romero Ben E, Cid JJ, Assali M, Fernández García E, Wellinger RE, et al. (2019) Surface modulation of single-walled carbon. Int J Nanomedicine 14: $3245-3263$

13. Saasa V, Malwel T, Beukes M, Mokgotho M, Liu CP, et al. (2018) Sensing technologies detection of acetone in human breath for diabetes diagnosis and monitoring. Diagnostics 8(1): 12

14. Sui L, Yu T, Zhao D, Cheng X, Zhang X, et al. (2020) In situ deposited hierarchical $\mathrm{CuO} / \mathrm{NiO}$ nanowall arrays film sensor with enhanced gas-sensing performance to $\mathrm{H}_{2} \mathrm{~S}$. Journal of Hazardous Materials 385: 121570

15. Nasiri N, Clark Ch (2019) Nanostructured sensors for medical and health applications: Low to high dimensional materials. Biosensors 9(1): 43.

16. Natale CD, Paolesse R, Martinelli E, Capuano R (2014) Solid-state gas sensors for breath analysis. Anal Chim Acta 824: 1-17.

17. Konstantinidi EM, Lappas AS, Tzortzi AS, Behrakis PK (2015) Exhaled Breath Condensate: Technical and Diagnostic Aspects. Nature Scientific World Journal 2015: 435160.

18. Lin T, Lv X, Hu Z, Xu A, Feng C (2019) Semiconductor metal oxides as chemoresistive sensors for detecting volatile organic compounds. Sensors 19(2): 233

19. Itoh T, Miwa T, Tsuruta A, Akamatsu T, Izu N, et al. (2016) Development of an Exhaled Breath Monitoring System with Semiconductive Gas Sensors, a Gas Condenser Unit, and Gas Chromatograph Columns. Sensors 16(11): 1891.

20. Schierbaum K (2016) Breath gas analysis. Chemical and Biochemical Sensors 2. Applications, Ullmann's Encylopedia of Industrial Chemistry, Wiley-VCH Verlag, Weinheim.

21. Jornet N, Henderson C, Campíns Falcó P, Daly R, Hall L (2019) Towards sarcosine determination in urine for prostatic carcinoma detection, Sens. Actuators B: Chemical 287: 380-389.

22. https://www.vivatmo.com/,07.2017

23. Stickstoffoxide.

24. Moon HG, Choi YR, Shim YS, Choi KI, Lee JH, et al. (2013) Extremely sensitive and selective NO probe based on villi-like WO3 nanostructures for application to exhaled breath analyzers. ACS Appl Mater Interfaces 5(21): 10591-10596

25. Koo WT, Choi SJ, Kim NH, Jang JS, Kim ID (2016) Catalyst-decorated hollow WO3 nanotubes using layer-by-layer self-assembly on polymeric nanofiber templates and their application in exhaled breath sensor. Sens Actuators B: Chemical 223: 301-310.

26. Cristescu SM, Mandon J, Harren FJM, Meriläinen P, Högman M (2013) Methods of NO detection in exhaled breath. J Breath Res 7: 017104.

27. Sun C, Maduraiveeran G, Dutta P (2013) Nitric oxide sensors using a combination of $\mathrm{p}$ - and n-type semiconducting oxides and its application for detecting NO in human breath. Sensors and Actuators B: Chemical 186: $117-125$.

28. Smith D, Španěl P (2017) On the importance of accurate quantification of individual volatile metabolites in exhaled breath. J Breath Res 11(4): 047106.

29. Li HY, Huang L, Wang XX, Lee CS, Yoon JW, et al. (2017) Molybdenum trioxide as a dual gas sensor for detecting trimethylamine and hydrogen sulfide. RSC Adv 7: 3680-3685.

30. Essiet IO (2013) Diagnosis of kidney failure by analysis of the concentration of ammonia in exhaled human breath. J Emerg Trends Eng Appl Sci 4(6): 859-862. 
31. Xu Z, Lei Shi, Yijin Wang, Jiyuan Zhang, Lei Huang, et al. (2020) Pathological findings of COVID-19 associated with acute respiratory distress syndrome, Lancet Respir Med 8: 420.

32. Yang, X, Yuan Yu, Jiqian Xu, Huaqing Shu, Jia'an Xia, et al. (2020) Clinical course and outcomes of critically ill patients with SARS-CoV-2 pneumonia in Wuhan, China: a single-centered, retrospective, observational study, ibid 8: 475.

33. Leung N, Daniel K W Chu, Eunice Y C Shiu, Kwok-Hung Chan, James J Mc Devitt, et al. (2020) Respiratory virus shedding in exhaled breath and efficacy of face masks, Nature Medicine, vol. 26, 676 (2020).

34. Khoubnasabjafari M, Rahimpour E, Jouyban A (2018) Exhaled breath condensate as an alternative sample for drug monitoring, Bioanalysis 10 (61).

35. Xu Z, Fangxia Shen, Xiaoguang Li, Yan Wu, Qi Chen, et al. (2012) Molecular and microscopic analysis of bacteria and viruses in exhaled breath collected using a simple impaction and condensing method. PLoS ONE 7: e41137.

36. Carpagnano GE, Mario Malerba, Donato Lacedonia, Antonia Susca, Antonio Logrieco, et al. (2016) Analysis of the fungal microbiome in exhaled breath condensate of patients with asthma, Allerg. Asthma Proc 37: 41 .

37. Mc Devitt JJ, Petros Koutrakis, Stephen T Ferguson, Jack M Wolfson, M Patricia Fabian, et al. (2013) Development and performance evaluation of an exhaled breath bioaerosol collector for influenza virus, Aerosol Sci. Technol 47: 444 .

38. Rahimpour E, Maryam Khoubnasabjafari, Vahid Jouyban-Gharamaleki, Abolghasem Jouyban (2018) Non-volatile compounds in exhaled breath condensate, Analytical and Bioanalytical Chemistry 410: 6411.

39. Rudnick SN, Mc Devitt JJ, First MW, Spengler JD (2019) Am J Infect Control 37: 813.

40. Lei Ch, Binxiao Su, Hailong Dong, Andrea Bellavia, Raffaele Di Fenza, et al. (2020) Protocol of a randomized controlled trial testing inhaled Nitric Oxide in mechanically ventilated patients with the severe acute respiratory syndrome in COVID-19 (SARS-CoV-2). MedRxiv.

41. Ma S, Jianfeng Jia, Yongtao Tian, Liangliang Cao, Shenlei Shi, et al. (2016) Improved $\mathrm{H} 2 \mathrm{~S}$ sensing properties of $\mathrm{Ag} / \mathrm{TiO} 2$ nanofibers. Ceram Int 42 : 2041.

42. Koo WT, Choi SJ, Jang JS, Kim ID (2017) Metal-Organic Framework Templated Synthesis of Ultrasmall Catalyst Loaded ZnO/ZnCo204 Hollow Spheres for Enhanced Gas Sensing Properties.Sci Rep 7.

43. Jang S, Choi SJ, Kim ID (2017) Fast Responding Exhaled-Breath Sensors Using W03 Hemitubes Functionalized by Graphene-Based Electronic Sensitizers for Diagnosis of Diseases. Sens. Actuators B241: 1276.

44. Kim NH (2016) Highly sensitive and selective acetone sensing performance of WO3 nanofibers functionalized by Rh203 nanoparticles. ibid B224: 185 .

45. Koo WT (2017) Metal-Organic Framework-Templated PdO-Co304 Nanocubes Functionalized by SWCNTs: Improved NO2 Reaction Kinetics on Flexible Heating Film, ACS Appl. Mater Interfaces 9: 8201.

46. Aroutiounian V (2014) Journal of Emerging Trends in Science and Technology 1: 1309.

47. Aroutiounian V (2020) Acetone sensor made of tin dioxide, J. Contemporary Physics-Arm. Acad Sci 55: 213-224.

48. Toyooka T, Hiyama S, Yamada Y (2013) A prototype portable breath acetone analyzer for monitoring fat loss. J Breath Res 7: 036005.

49. Jang JS, Choi SJ, Kim SJ, Hakim M, Kim ID (2016) Rational Design of Highly Porous SnO2 Nanotubes Functionalized with Biomimetic Nanocatalysts for Direct Observation of Simulated Diabetes. Adv Funct Mater 26: 4740.

50. Xishuang Liang, Tae Hyung Kim, Ji Wook Yoon, Chang Hoon Kwak, Jong Heun Lee (2015) Ultrasensitive and ultraselective detection of H2S using electrospun CuO-loaded In203 nanofiber sensors assisted by pulse heating, Sens. Actuators B209: 934

51. Yoneda M, Suzuki N, Hirofuji T (2015) Current Status of the Techniques Used for Halitosis Analysis, Austin Chromatogr 2: 1024.

52. Wang JF, Li Y, Song JN, Pang HG (2014) Role of hydrogen sulfide in secondary neuronal injury. Neurochem Int 64: 37.

53. Aroutiounian VM (2009) Improvement and Stabilization of Thinfilm Hydrogen Sensors Parameters, Advanced Sensors for Safety and Security, NATO Science for Peace and Security Series B: Physics and Biophysics, chapter 9: 105-124.

54. Aroutiounian VM (2012) Hydrogen sensors, Dekker Encyclopedia of Nanoscience and Nanotechnology, Second Edition, Taylor and Francis, NY, USA.

55. Aroutiounian VM (2007) Metal oxide hydrogen, oxygen, and carbon monoxide sensors for hydrogen setups and cells. Intl J Hydrogen Energy 32: 1005-1012.

56. Aroutiounian VM (2016) Graphene- and graphene-oxide-based gas sensors. In: Graphene Science Handbook. Applications and Industrialization, CRC Press Tailor and Francis Group, USA, Fl., Boca Raton, Chapter 20: 299-310

57. Aroutiounian VM (2018) Properties of hydrogen peroxide sensors made from nanocrystalline materials. Sensors and Transducers 223: 9-21.

58. Aroutiounian VM (2018) Semiconductor gas sensors made from metal oxides functionalized with carbon nanotubes. ibid 228: 1-16.

59. Aroutiounian V, Valeri Arakelyan, Mikayel Aleksanyan, Gohar Shahnazaryan, Petr Kacer, et al. (2018) Thin-film SnO2 and ZnO detectors of hydrogen peroxide vapors, J. Sens. Sens. Syst 7: 281-288.

60. Aroutiounian VM, Valeri M Arakelyan, Gohar E Shahnazaryan, Mikayel S Aleksanyan, Klara Hernadi, et al. (2015) The ethanol sensors made from $\alpha$-Fe203 decorated with multiwall carbon nanotubes, Advances in Nano Research 1: 1-15

61. Alvi MA, Madani JH, Kumar (2019) Synthesis and characterization of SWCNTs/ZnO hybrid nanocomposite for sensor applications Mater. Res. Express 6: 1-9.

62. Yang J, Nie Q, Liu H, Xian M, Liu H (2016) A novel MVA-mediated pathway for isoprene production in engineered E. coli.BMC Biotech 16(5).

63. O Brien PJ, Siraki AG, Shangari N (2005) Aldehyde sources, metabolism, molecular toxicity mechanisms, and possible effects on human health. Crit Rev Toxicol 35: 609.

64. Reef EA, Morad K Nakhleh, Orna Barash, Hossam Haick (2019) Breath analysis of cancer in the present and the future Eur Respir Rev 28: 190002

65. Tiele A, Alfian Wicaksono, Jiten Kansara, Ramesh P Arasaradnam, James A Covington (2019) Breath Analysis Using eNose and Ion Mobility Technology to Diagnose Inflammatory Bowel Disease-A Pilot Study Biosensors 19: 55-70.

66. Constanzo S (2019) Software-Defined Doopler radar sensors for human breathing detection Sensors 19: 3085-3094.

67. Majumder S, Deen M (2019) Smartphone Sensors for Health Monitoring and Diagnosis. Sensors (Basel): 2164-2209.

68. Arouitiounian V, Hovhannisian A (2020) Breath Semiconductor Metal Oxide Gas Detector using Arduino Nano, Biomed. J Sci Tech Res 27: 20452-20453.

69. Arouitiounian V (2020) Microelectronic gas sensors for non-invasive analysis of exhaled, gases Medicine in Armenia 60: 3-15

70. Arouitiounian V (2018) Semiconductor gas sensors for detection of chemical warfare agents and toxic industrial chemicals. International Scientific Journal for Alternative Energy and Ecology 249-251: 38.

71. Hovhanniisisyan A (2020) Semiconductor Metal Oxide Gas Detector using Arduino Magister thesis, YSU, 2020 (in Armenian). 
ISSN: 2574-1241

DOI: $10.26717 /$ BJSTR.2020.29.004780

Aroutiounian VM. Biomed J Sci \& Tech Res

(C) (i) This work is licensed under Creative Submission Link: https://biomedres.us/submit-manuscript.php

\begin{tabular}{ll} 
BIOMEDICAL & Assets of Publishing with us \\
RESEARCHES & - Global archiving of articles \\
\hline Immediate, unrestricted online access \\
\end{tabular}

